\section{Figure S4A}
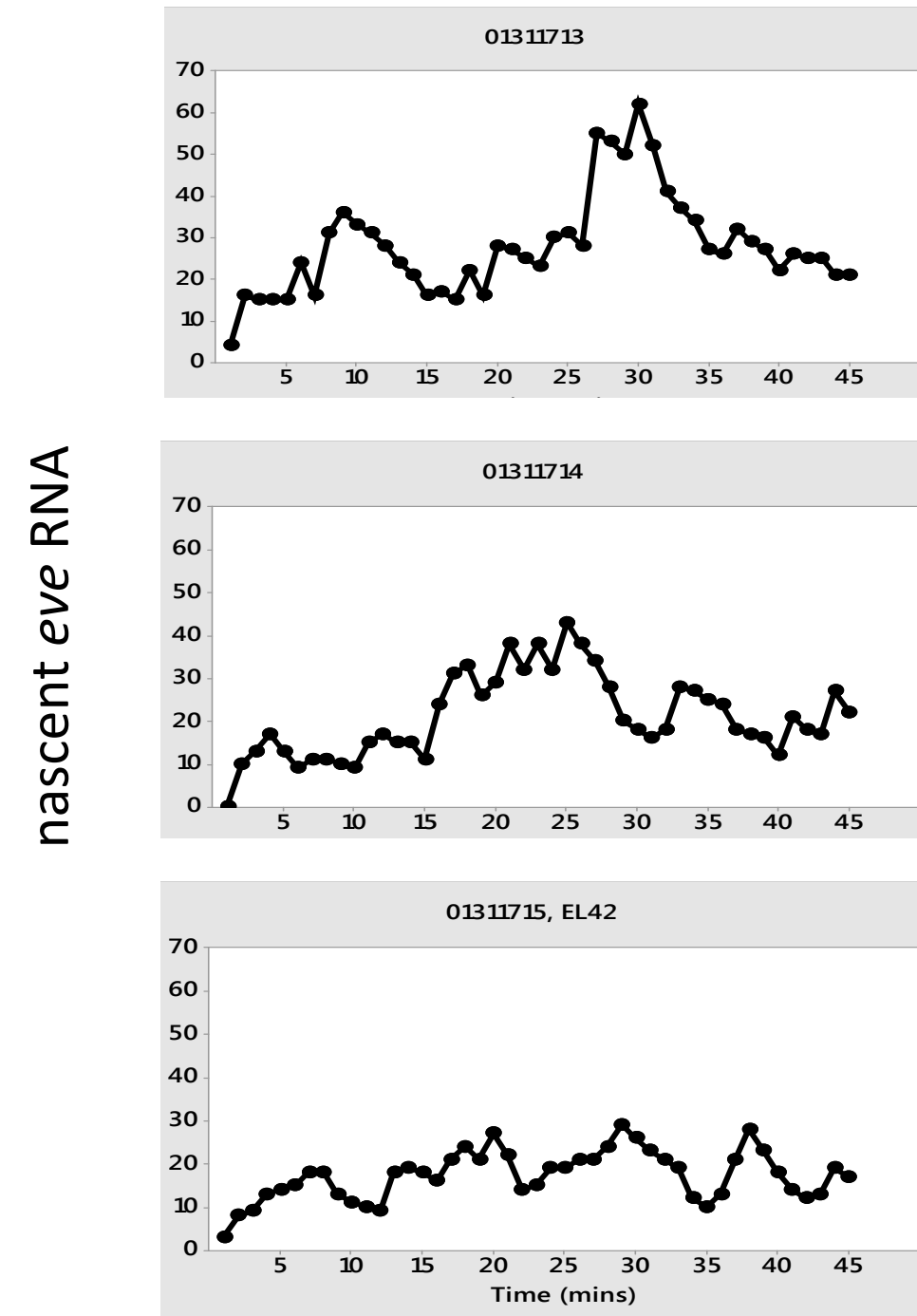
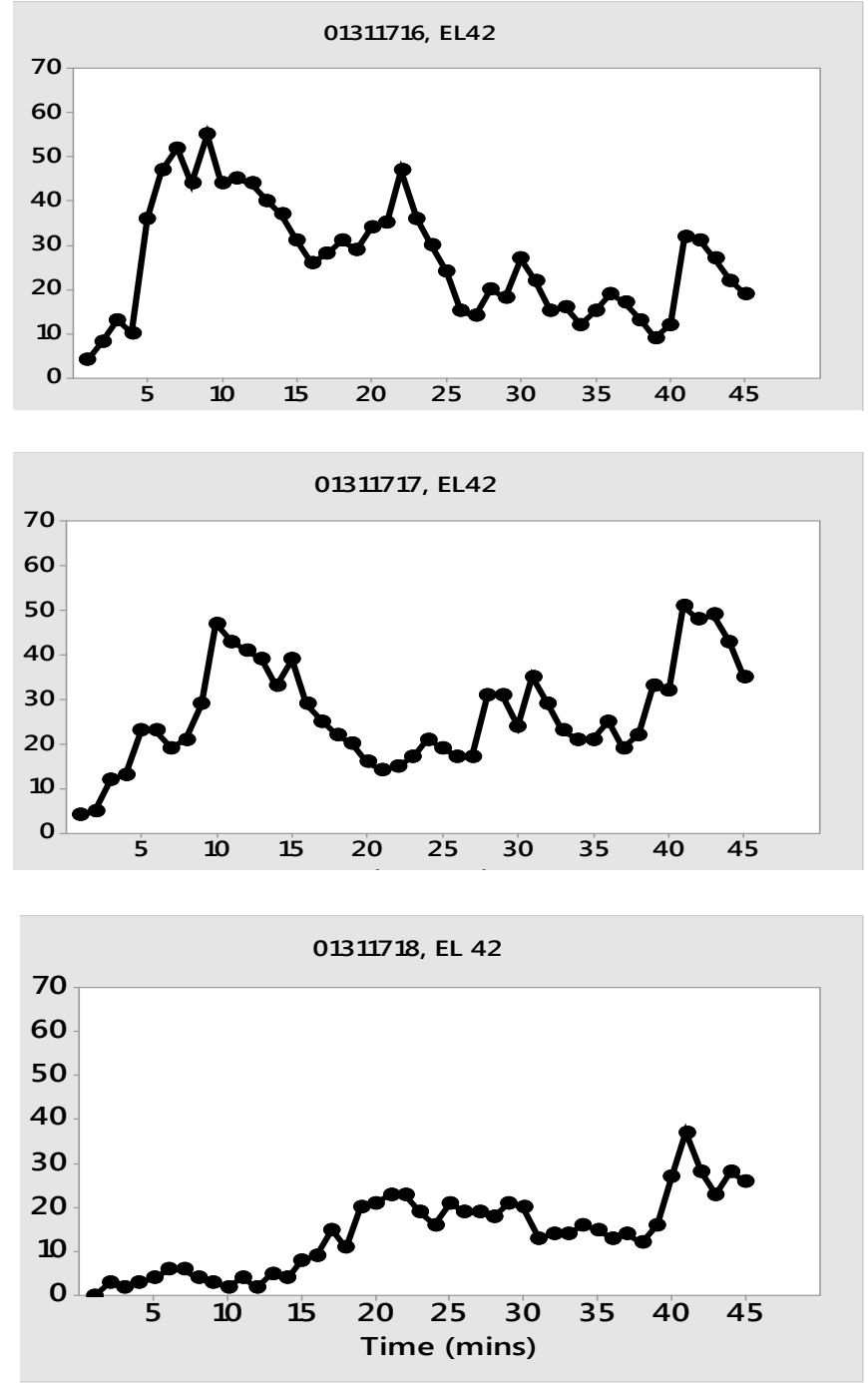
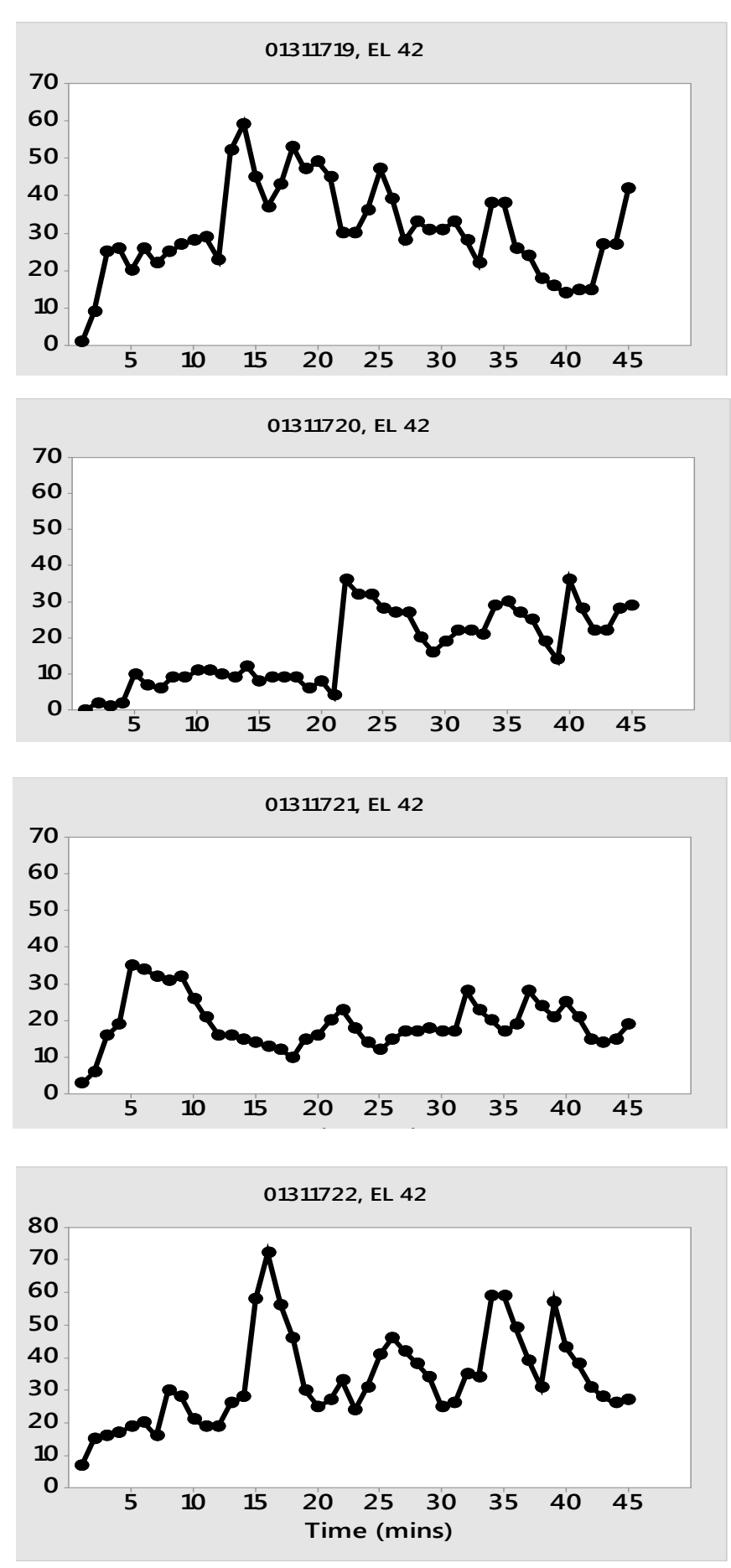


\section{Figure S4B}
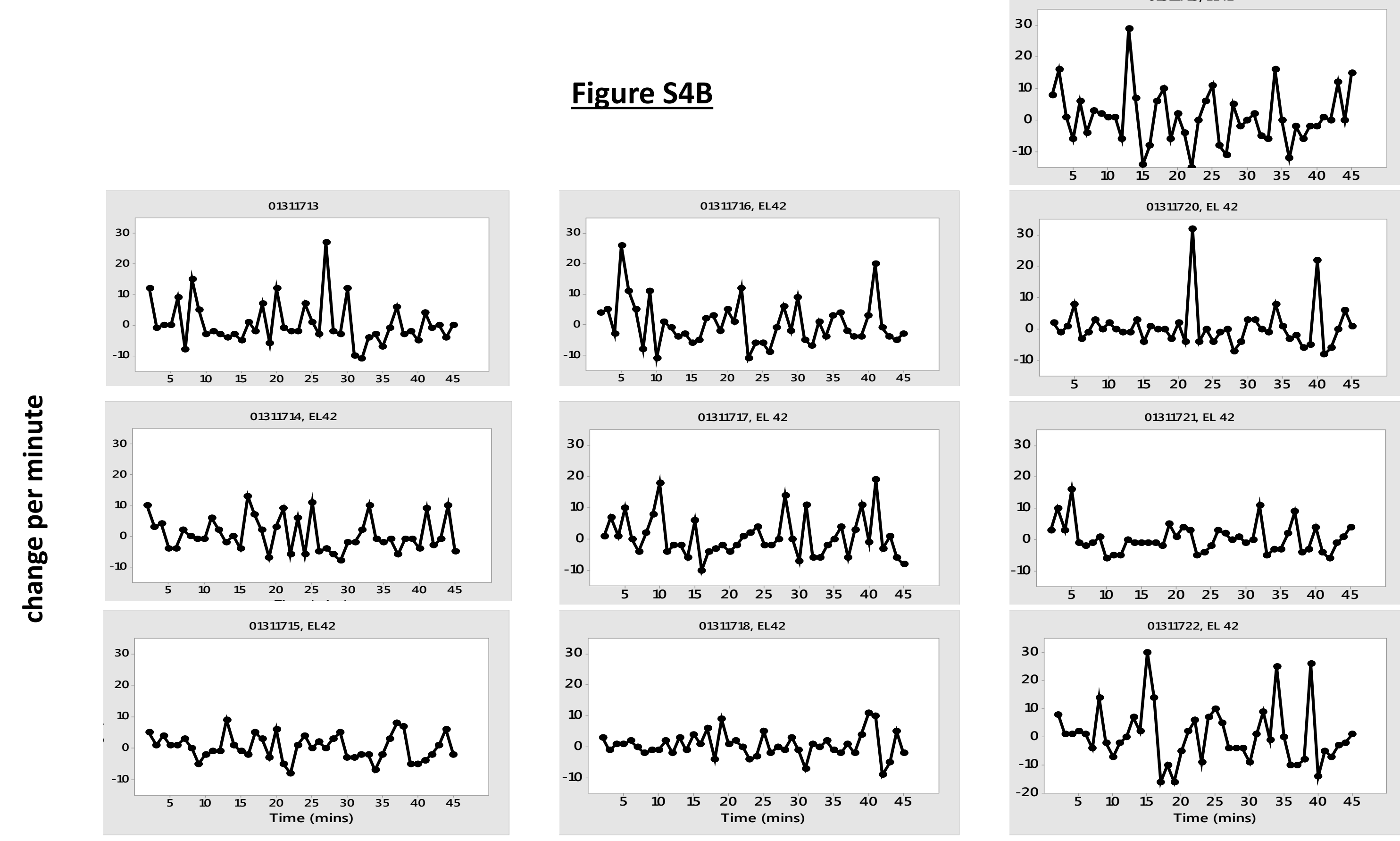


\section{Figure S4C}

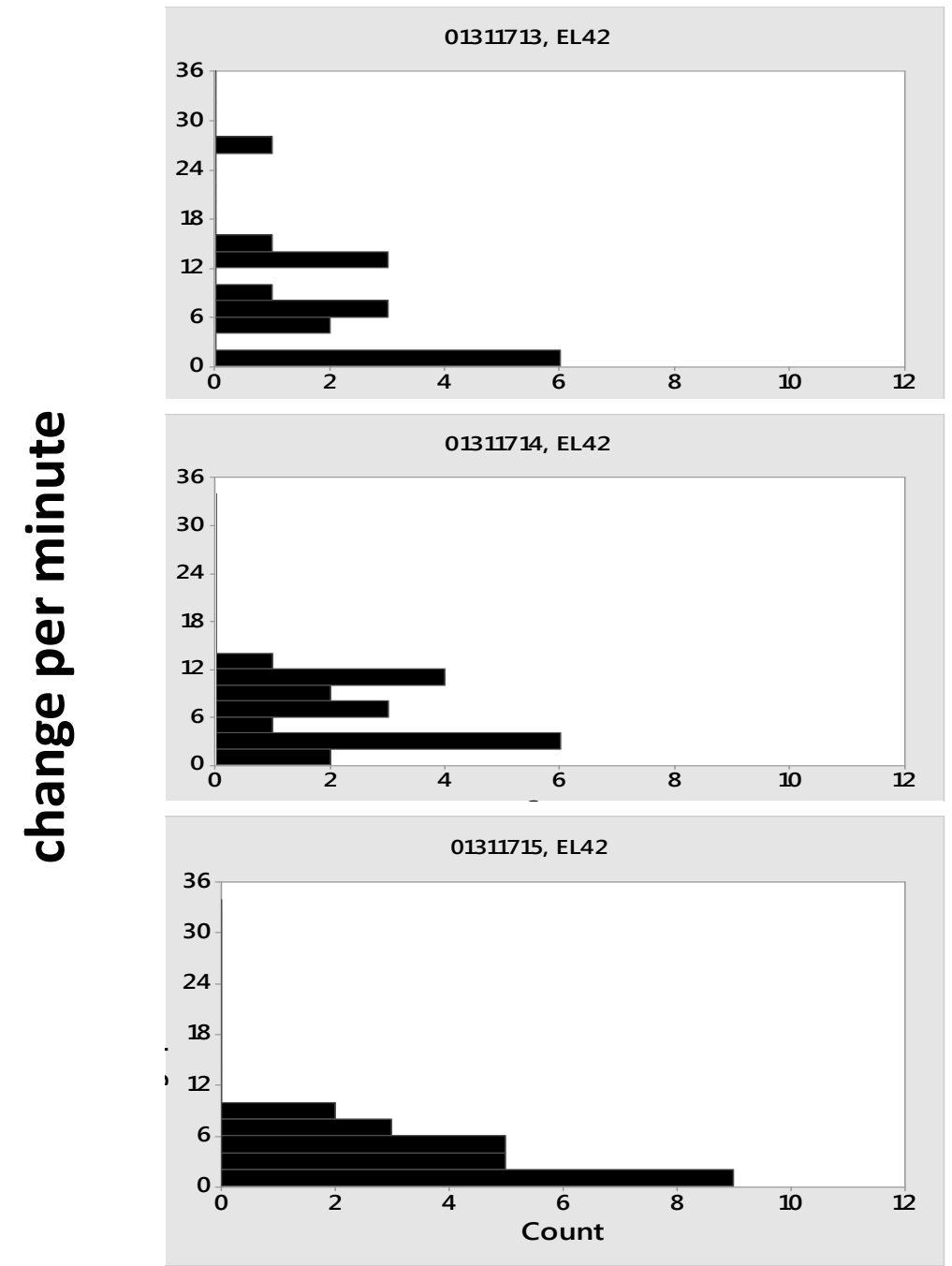

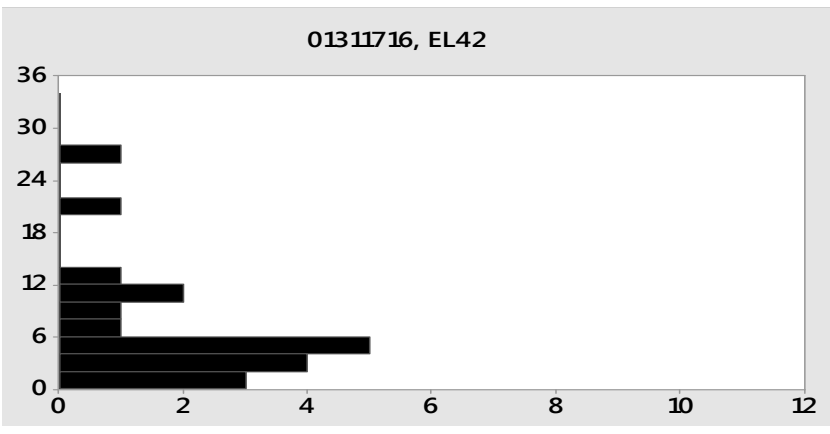
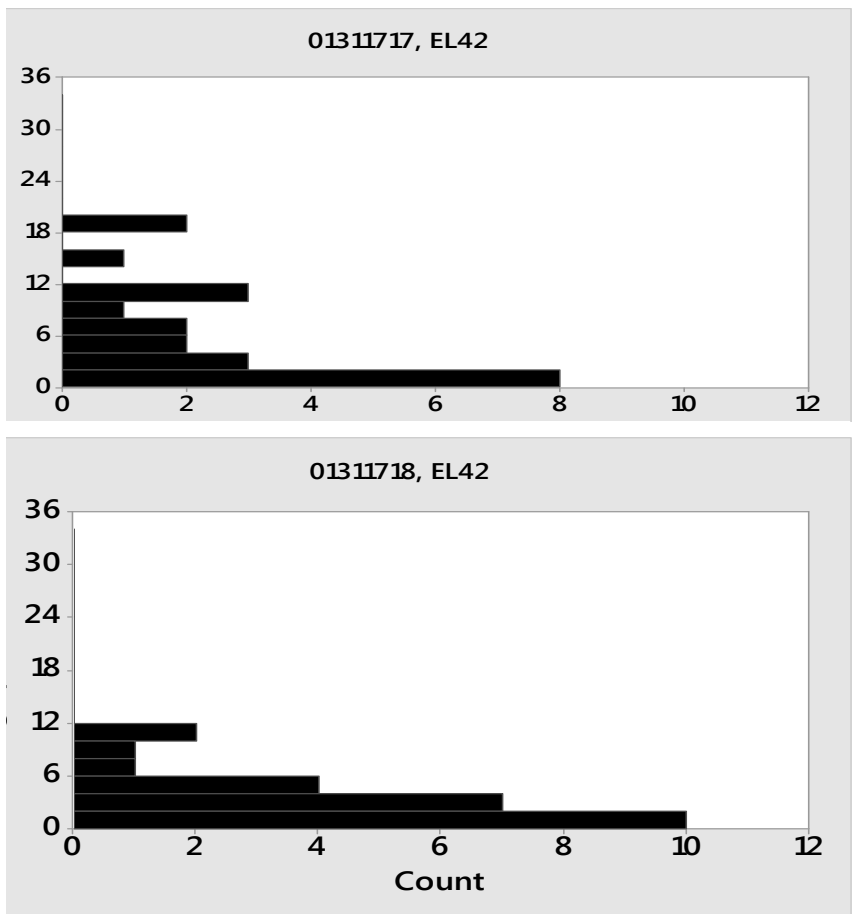
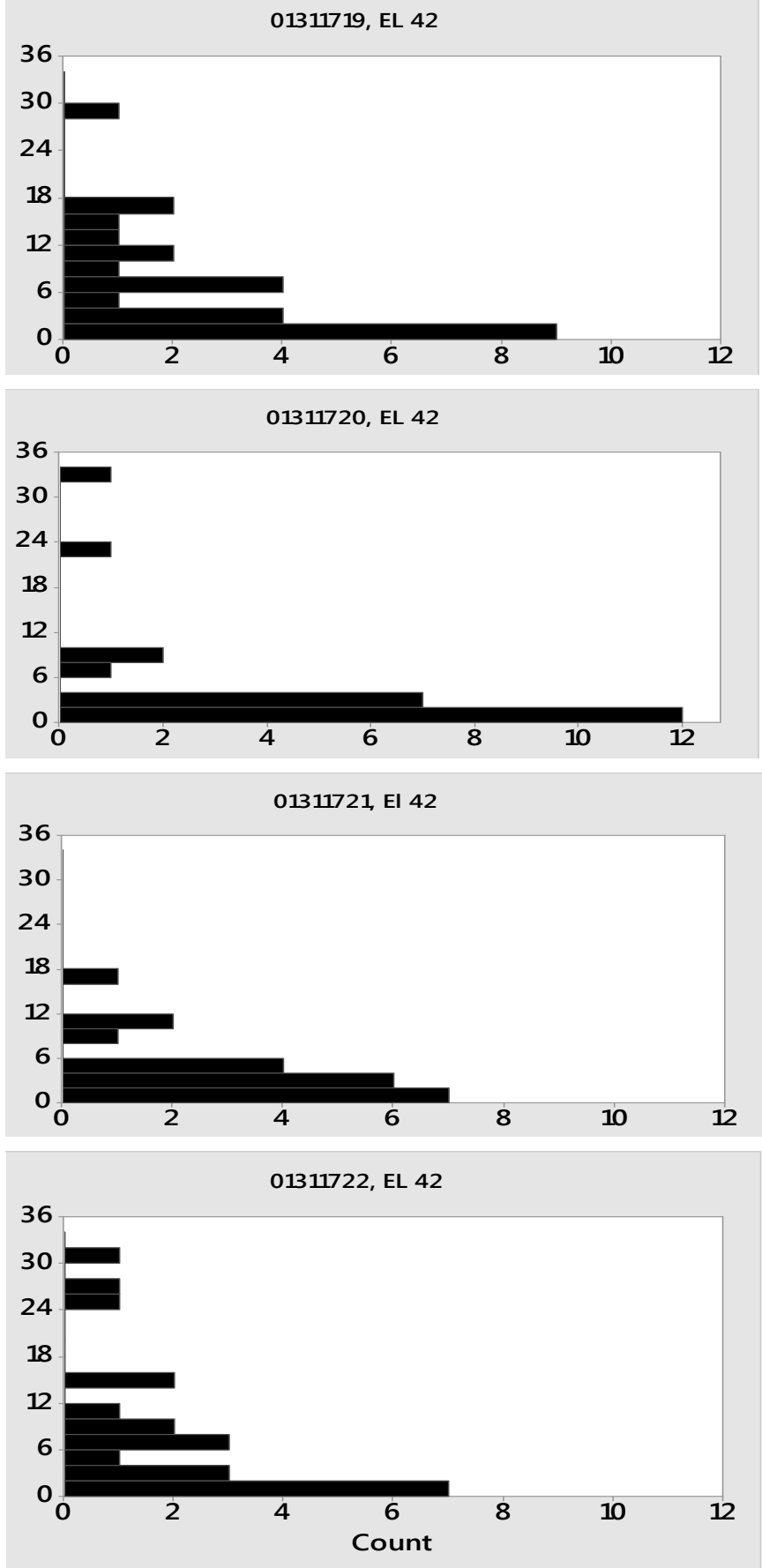